\title{
TEMA 9-2013: Infecciones óseas Primarias. Osteomielitis agudas y crónicas. Infecciones específicas
}

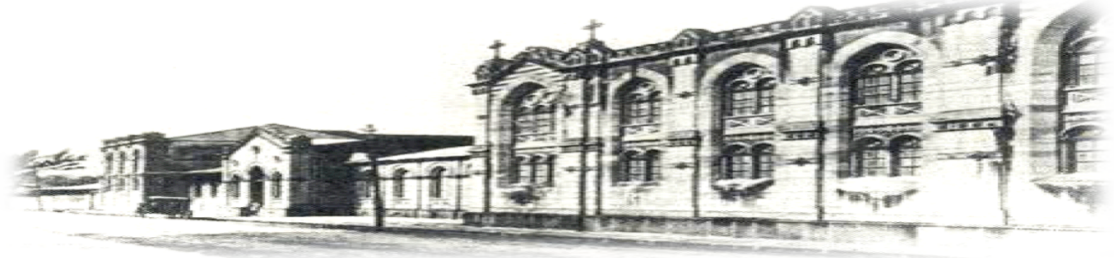

Haspital San Guan de Dias. San José, Costa Rica. Fundado en 1845

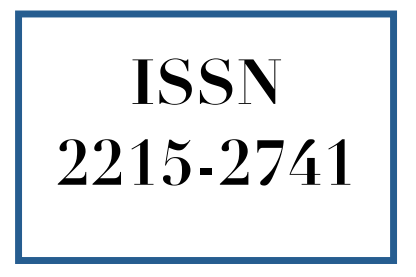

Daniela Jiménez Soto ${ }^{1}$ Javier Soto Fallas ${ }^{2}$

${ }^{1}$ Médico General UCIMED. Correo electrónico: danajs2509@hotmail.com

${ }^{2}$ Médico Especialista en Ortopedia y Traumatología. Asistente del Servicio de Ortopedia. Sección de Cirugía. Hospital San Juan de Dios.

\section{RESUMEN}

La osteomielitis es una entidad cínica inflamatoria, progresiva, por infección y nueva aposición de hueso, que en la gran mayoría de casos es provocada por gérmenes piógenos. Este artículo se basa en una revisión de tema, donde se desarrollan puntos importantes en cuanto a la fisiopatología y características de cada huésped, gérmenes y antibioticoterapia. El objetivo principal es permitir una mejor comprensión, para dar a un diagnóstico acertado lo más rápido posible, ya que el tratamiento debe de ser temprano, para lograr mayor efectividad.

\section{PALABRAS CLAVE}

Osteomielitis. Fisiopatología. Inmunodeficiencia. Antibióticos.

\begin{abstract}
Osteomyelitis is a progressive and inflammatory clinical entity, characterized for infection and new bone apposition that in the vast majority of cases is caused by pyogenic germs. This article is based on a review of clinical issues, where they develop important points regarding the pathophysiology and characteristics of each guest, germs and antibiotics. The purpose of this review is allow us a better compression, to give an accurate diagnosis as quickly as possible, because the treatment must be immediate to be more effective.
\end{abstract}

\section{KEY WORDS}

Osteomyelitis. Pathophysiology. Immunodeficiency. Antibiotics. 


\section{Introducción}

En los últimos años, la osteomielitis aguda ha presentado una disminución en la incidencia por el uso oportuno de antibióticos. Por otro lado, se ha documentado un aumento de incidencia de casos de osteomielitis crónica, postraumáticas o por implantes. La infección asociada a una prótesis puede producirse dentro de las primeras 12 semanas a partir de la cirugía (infección aguda), dentro de 24 meses (infección crónica, a menudo con microorganismos menos virulentos) y en pacientes con infección hematógena, incluso más tarde ${ }^{(1)}$.

También se ha visto un aumento en los casos de rebrote de osteomielitis granulomatosa por tuberculosis, gérmenes Gram negativos y hongos (Inmunodeprimidos-VIH) $^{(7)}$.

\section{DISCUSIÓN}

\section{Clasificación}

Su clasificación varía según el acceso del germen, ya sea hematógena (foco distante), directa (herida o punción) o por contigüidad de un foco adyacente (partes blandas por ejemplo). En cuanto al tiempo de curso clínico (duración de las manifestaciones), es discutido por los autores: agudas (menos de 6 semanas) o crónicas (más de 6 semanas $)^{(7)}$.

\section{Osteomielitis Aguda Hematógena (OAH)}

Se define como la inflamación del hueso causada por bacterias que llegan al mismo a través de la sangre, partiendo de un foco lejano. Se utiliza el concepto cuando clínicamente es una infección recién reconocida. La recaída de una infección previamente tratada no es considerada como un signo de enfermedad crónica; si persiste por más de 10 días, se correlaciona con el desarrollo de un hueso necrótico y con osteomielitis crónica ${ }^{(1)}$.

\section{Epidemiología}

Predominio en el sexo masculino con una relación 3:1 en algunas series, aunque en los últimos tiempos ha tendido a igualarse. La edad pico de mayor incidencia se da entre el primer año de vida y los 16 años, sobre todo en metáfisis de huesos largos (predominio en rodilla $)^{(8)}$. Es muy rara en adultos y si se da, es por enfermedades predisponentes, las más frecuentes en adictos a drogas vía parenteral, artritis reumática e inmunodeprimidos. Se presenta sobre todo en vértebras y a veces en diáfisis de huesos largos. En los pacientes adictos a drogas de uso parenteral se ven más afectadas las vértebras (por lo general es el cuerpo vertebral el afectado), articulaciones sacroilíacas, esternoclaviculares y sínfisis púbica ${ }^{(4)}$.

\section{Factores Predisponentes}

a. Sociales: Aumenta con el subdesarrollo.

b. Climáticos. Aumenta en primavera y otoño (no se conoce la causa).

c. Traumáticos: Por estasis vascular tras traumatismo (no demostrado). Para considerarlo, debe haber un trauma antes de los 6 a 8 días.

d. Higiénicos-dietéticos: Aumenta con el déficit de vitamina $\mathrm{C}$ y de proteínas.

e. Hemoglobinopatías: Aumenta con talasemia y drepanocitosis (en este caso el germen causal casi siempre es Salmonella $s p)^{(4,5,7-9)}$.

f. Inmunitarios: Aumenta en inmunodeprimidos (Micobacterias no tuberculosas y hongos) ${ }^{(4,5,9)}$.

g. Vía parenteral/catéter: Uso de drogas ilícitas, adictos a drogas inyectables (asociado a Pseudomonas aeruginosa) o uso de catéteres contaminados (infecciones fúngicas como Candida $s p)^{(1,4,5)}$.

h. Pie diabético: Lo más común son los cocos gram positivos, especialmente Staphylococcus $^{(3,7)}$.

i. Herida punzante en planta del pie: Por lo general a través del calzado (Pseudomonas aeuroginosa $)^{(4,8)}$.

j. Material de osteosíntesis y/o prótesis: Puede pasar desapercibida y puede dar lugar a una prótesis no funcional con osteomielitis crónica (Staphylococcus epidermidis en el $40 \%$ de los casos; otros con menor frecuencia son $S$. aureus, Streptococcus sp. y BGN en infección nosocomial) ${ }^{(4,5,7,8)}$.

k. Úlceras de decúbito en pacientes encama$\operatorname{dos}^{(5)}$.

1. Mordedura de animales (Pasteurella multoci$d a)^{(7)}$.

\section{Patogenia}

La puerta entrada es a través de un foco séptico, que en un $30 \%$ de los casos pasa desapercibido. Posteriormente se da la propagación hematógena, 
principalmente de dos formas: septicemia (grandes cantidades) y raptus bacterémico (pequeñas cantidades).

La principal causa de infección es el Staphylococcus aureus, que se adhiere al hueso mediante la expresión de receptores (Adhesinas) para los componentes de la matriz ósea (compuesta por fibronectina, laminina, colágeno y sialoglicoproteinas). La expresión de la adhesina de unión a colágeno permite la unión del patógeno al cartílago.

El $S$. aureus tiene la característica de supervivencia intracelular en el osteoblasto, ésto explica la persistencia de la bacteria en el hueso. Una vez que los microorganismos se adhieren, expresan resistencia fenotípica a los antimicrobianos, lo que también puede explicar la alta tasa de fracaso de ciclos cortos de tratamiento $^{(1,5)}$

Se ha visto una relación de la pérdida ósea de la osteomielitis con las metaloproteasas de la matriz. Estas enzimas son secretadas por células mesenquimales del estroma y osteoblastos, con el fin de degradar la matriz y para activar la función de los osteoclastos; produciendo así un aumento de la resorción ósea y la progresión de la enfermedad ${ }^{(5,7)}$.

El proceso de anidamiento en el hueso se ve favorecido por la escasez de mecanismos de defensa, el patrón vascular propio y la rigidez del mismo hueso. El predominio en metáfisis se asocia a los lagos venosos, donde se remansa la sangre y el endotelio capilar pierde la capacidad fagocitaria.

El traumatismo produce micronecrosis y estasis vascular $^{(7)}$.

\section{Circulación metafisaria según la edad y localización}

De los 12 a los 18 meses de edad la circulación epifisiaria y diafisiaria se comunican de modo que la infección puede progresar a la epífisis y el periostio es laxo, lo que hace que se desprenda con facilidad $^{(9)}$

Desde el año de edad hasta los 16 o 18 años, la fisis hace las veces de barrera a la propagación de la infección, con excepción de la cadera, el codo, el húmero proximal y el tobillo. En estos sitios la cápsula articular es muy grande e incluye la metáfisis, lo que puede llevar a artritis e infectar a la epífisis ${ }^{(9)}$.

En adultos la fisis desaparece, pero de igual manera la infección puede propagarse. El periostio se encuentra muy adherido y no se despega con facilidad. No hay presencia de lagos venosos, por lo que la incidencia de infección es más baja.

En la columna vertebral es causada comúnmente por siembras hematógenas. La fisiopatología refleja la anatomía venosa, que permite un flujo retrógrado del plexo pélvico debido a la falta de estructuras valvulares, proporcionando mayor oportunidad de invasión bacteriana ${ }^{(5,7)}$.

Las infecciones son predominantemente localizadas en columna lumbar y torácica, menos frecuente en columna cervical. En los niños, los vasos sanguíneos de la columna pasan a través del cartílago epifisiario y terminan dentro del disco intervertebral, lo que permite la infección a partir de la vasculatura ósea (Discitis pediátrica) ${ }^{(5,7)}$.

\section{Anatomía Patológica}

La fase vascular se caracteriza por que las arterias nutricias se vacían en las venas sinusoidales, produciendo un flujo lento y turbulento en los lagos venosos. Se convierte así en un depósito de gérmenes ${ }^{(2,5,7)}$. Hay carencia de anastomosis en las ramas terminales, produciendo obstrucción que favorece el desarrollo de necrosis ${ }^{(7)}$.

En la fase de desarrollo hay hiperemia y edema en las zonas inextensibles. Aumenta la presión y esto ocluye los vasos intraóseos. La infección se extiende por los canales de Havers y Volkmann hasta la zona subperióstica. Se llega infecta la médula ósea, pero ésta presenta células fagocíticas que producen una reacción inflamatoria, donde se sella el espacio medular y obliga a la difusión perióstica. En el periostio la tensión es baja y la actividad fagocítica está alterada $^{(2,7)}$.

La última fase corresponde a la de difusión. En ésta, el absceso se despega del periostio por la isquemia y las zonas necróticas, alrededor de las cuales se forma tejido de granulación, donde se reabsorbe el hueso periférico y se forman los secuestros (zonas de hueso necrótico aisladas del 
resto $)^{(5,7,9)}$. El periostio forma delgadas capas o densos tabiques alrededor de secuestros (involucro).

Las fibras de Sharpey que unen el periostio con el hueso se osifican y forman una imagen radiográfica de fuego de hierbas o sol naciente, que se puede confundir con un tumor ${ }^{(9)}$.

\section{Evolución}

Si el absceso se evacúa espontáneamente y el secuestro a través de partes blandas, se puede producir la resolución espontánea. El involucro fistuliza y da lugar a las cloacas de Weidman (o foraminas de Troja). A veces, los abscesos cronifican y pueden invadir la diáfisis, a lo que se le conoce como pandiafisitis o pueden llegar a extenderse a otras zonas.

\section{Clínica}

El comienzo suele ser brusco, con fiebre alta, dolor intenso inflamatorio y persistente. Frecuentemente monostótitco (un solo hueso afectado, sobre todo tibia, fémur o húmero) ${ }^{(10)}$

Si el hueso es superficial presenta tumefacción, eritema y aumento de la temperatura local. Dolor a punta de dedo (al tocar, le atraviesa el dolor). La movilidad pasiva de articulaciones permite diferenciar un cuadro de artritis séptica (en la artritis no está conservada la movilidad pasiva, por la distensión articular y la contractura muscular refleja). En ambos casos duele a la movilización.

En los recién nacidos y lactantes es frecuente encontrar cuadros insidiosos. Suele afectar el húmero con mayor frecuencia ${ }^{(4)}$. Pueden presentar pseudoparálisis de un miembro o una contractura fija de una articulación (osteomielitis $\mathrm{y}$ artritis).

En los adultos el cuadro es más aparente, siempre debe sospecharse en pacientes con historia de enfermedades crónicas o inmunodepresión. El diagnóstico es difícil en localizaciones profundas como cadera, pelvis o columna. Presenta sintomatología abdominal que puede llegar a confundir. Cuando implica infección de dos vértebras adyacentes y el disco que se ubica entre ellas, los síntomas más frecuentes son dolor de cuello, espalda y fiebre ${ }^{(1)}$.
En el caso de las infecciones asociadas a prótesis por lo general hay poco o nada de fiebre; presentan dolor e inestabilidad en la articulación. Se les debe pedir aspirado de líquido del espacio artificial de la articulación, tinción de Gram y cultivo cuantitativo $^{(1,7)}$.

Pese a que muchos estudios no encuentran una asociación entre la osteomielitis con neuropatía periférica, por diabetes o enfermedad vascular, se debe de sospechar en algunos $\operatorname{casos}^{(5)}$. En estos pacientes se puede observar la piel con ulceración o trauma ${ }^{(1,3)}$, afección que predomina a nivel de pies, sobre todo en las cabezas de metatarsianos y huesos del tarso. Puede no haber dolor por la avanzada neuropatía. Se puede observar mínima celulitis en los casos donde la infección avanzó progresivamente hacia madrigueras, que van camino al hueso subyacente. Si se logra avanzar una sonda estéril suavemente que llegue hasta el hueso, es diagnóstico claro de osteomielitis hasta no demostrar lo contrario.

En pacientes con antecedente de claudicación intermitente de la marcha hay que sospechar isquemia grave $y$ se les debe realizar arteriografía, incluyendo toda la vascularización del pie ${ }^{(1,7)}$.

En casos de infección de la columna vertebral, el dolor en la espalda es el síntoma inicial más común y la fiebre no siempre está presente. El sitio más común de afección en columna es la zona lumbar $(58 \%)$, columna torácica $(30 \%)$ y cervical (11\%). Cuando el dolor de espalda es severo y agudo, por lo general sugiere la presencia de absceso epidural $^{(11)}$.

\section{Pruebas complementarias}

\section{Laboratorio}

Aumento de la velocidad de eritrosedimentación (VES) en el 95\% de los casos, desde el segundo día y tiende a normalizarse a partir del los 10 a 14 días de tratamiento antibiótico ${ }^{(4,10)}$. Leucocitosis con desviación a la izquierda en 25 a $65 \%$ de los casos. Puede darse un aumento de la lipemia y lipiduria, por destrucción de grasa del hueso.

La PCR suele ser útil para ver la respuesta al tratamiento (mejor que la VES). El aumento y descenso es más rápido. Se eleva en las primeras 
6 horas y alcanza valores máximos a las 48 a 72 horas. Puede descender a las 6 horas de tratamiento adecuado y normalizarse a los 7 días. Siempre debe ir disminuyendo con el $\operatorname{tratamiento}^{(4,10)}$.

\section{Microbiología}

Los hemocultivos (antes de poner el tratamiento) son positivos en el 50 a $75 \%$ de los casos) y se deben de repetir sistemáticamente: si son negativos con alta sospecha, está indicado realizar biopsia con aguja, que se envía para análisis histopatológico y si existe la posibilidad de fallo, se debe de tomar una segunda biopsia guiada por tomografía.

En caso de segundo fallo para establecer el diagnóstico, las alternativas son: terapia empírica o una biopsia quirúrgica abierta ${ }^{(1)}$.

En la punción y aspiración ósea, el cultivo es positivo en el 60 a $70 \%$ de los $\operatorname{casos}^{(4)}$. Conjuntamente, con ambos cultivos se alcanza un $75 \%$ de rentabilidad para el diagnóstico etiológico. La biopsia es el estudio anatomopatológico del hueso por excelencia y permite hacer el diagnóstico diferencial con otras patologías como la de origen tumoral ${ }^{(4)}$.

\section{Radiografía}

Puede ser normal en los primeros 10 días y es bastante útil para descartar otras patologías como fracturas y tumores ${ }^{(4)}$. Inicialmente se observa densificación y tumefacción de partes blandas. Después de 10 días se puede observar neoformación perióstica laminar y a las 2 a 6 semanas ya se diferencian zonas líticas. Los secuestros se suelen observar a partir de la tercera semana.

\section{Gamagrafía}

El difosfonato de tecnecio 99 metaestable es el recomendado. La hipercaptación en el $95 \%$ de los casos se da en las primeras 24 horas. El radiofármaco se une a los sitios de aumento de la actividad metabólica ósea y es altamente sensible para la detección temprana de osteomielitis aguda, más no específica ${ }^{(1,10)}$. No es útil como criterio evolutivo ya que las imágenes pueden persistir varios meses ${ }^{(4)}$.
El estudio con leucocitos o inmunoglobulinas marcadas con citrato de galio $67 \mathrm{o}$ indio $111 \mathrm{es}$ menos sensible pero más específico y confirma los resultados del tecnecio.

\section{Ecografía}

Hay que valorar la participación de partes blandas y es bastante útil para detectar pus subperióstico.

\section{Tomografía Computarizada}

Es muy propenso a la degradación de la imagen, debido a los artefactos causados por la presencia de hueso o metales ${ }^{(1,10)}$. Es muy útil para guiar la biopsia con aguja ${ }^{(1)}$.

\section{Resonancia Magnética}

Tan sensible como la gammagrafía y con excelente resolución. Detecta cambios precoces en hueso, como reacción perióstica, destrucción cortical y daño articular. También se puede observar la destrucción de la médula ósea, la participación de tejidos blandos y el edema (antes que en la radiografía) ${ }^{(1)}$. Es la Técnica de elección para las vértebras. En general es poco específica, demuestra edema (baja señal en T1 y aumentada en T2) y puede diferenciar entre osteomielitis aguda y crónica.

\section{Grados de seguridad diagnóstica}

- OAH firme: polimorfonucleares en la biopsia, con cultivo y tinción Gram positivos.

- OAH probable: clínica, analítica y radiografía sugestivas, así como hemocultivos positivos.

- OAH posible: respuesta satisfactoria al tratamiento con antibióticos en pacientes con clínica, analítica y radiografía sugerente.

\section{Diagnóstico diferencial}

Entre los diagnósticos que se deben descartar está la fiebre reumática con predominio articular, afección cardiaca y hemocultivos negativos. La artritis reumatoide tiende a ser de predominio articular y poliarticular. En el caso de que fuese por traumatismo, mediante radiología convencional se puede diferenciar sin ningún problema. 
Los procesos tumorales, sobre todo el sarcoma de Ewing debe ser descartado. Es un cuadro muy parecido a la OAH, suele ser localizado predominantemente en metáfisis, se puede ver en niños entre los 7 y 15 años, afección del estado general y aumento de la VES. Lo que diferencia al sarcoma de Ewing de la $\mathrm{OAH}$, es la aparición radiológica de osteoporosis difusa, aumento de la fosfatasa alcalina y la presencia de metástasis.

Otros diagnósticos diferenciales incluyen la artritis séptica, la tuberculosis (predominio epifisiario y articular) y la sinovitis transitoria de cadera. Son entidades que usualmente cursan sin afectación general y tienen regresión en pocos días.

\section{Complicaciones}

Una de las complicaciones de la osteomielitis son los senos crónicos. Son abscesos con presencia de hueso expuesto, pérdida de la integridad estructural y crecimiento de perturbaciones. Suelen romperse a través de la piel $^{(9)}$. También se puede observar abscesos, fístulas y artritis, si la metáfisis afectada está dentro del espacio articular ${ }^{(4)}$.

Puede haber dismetría, ya sea un aumento de la longitud por aumento de actividad de la fisis por la hiperemia o disminución de la longitud (más frecuent) por la disminución de crecimiento debido a la destrucción de la fisis. Se puede dar desprendimiento epifisiario si se debilita la unión epifisio-diafisiaria y en algunos casos puede producirse fracturas por debilidad del hueso afectado.

La cronificación provoca la úlcera de Majorlin (carcinoma espinocelular de mal pronóstico). Excepcionalmente puede presentarse un síndrome nefrótico secundario a una glomerulopatía membrano proliferativa ${ }^{(7)}$.

\section{Tratamiento}

Lo más importante en el tratamiento es la antibioticoterapia. Se debe iniciar tratamiento empírico intravenoso y éste debe ser ajustado a la sensibilidad del antibiograma ${ }^{(4)}$. Una vez que se conoce el germen, el inicio debe de ser precoz, a dosis altas inicialmente y de forma intravenosa, pasando a oral en niños a los 5 a 10 días (si hay mejoría clínica y/o de PCR) y en adultos más tarde (usualmente no se toleran dosis tan altas por vía oral).

Se debe administrar dosis intravenosas elevadas ya que la penetración ósea de muchos antibióticos es muy pobre. Estas dosis se dan hasta que se conozca el microorganismo y la Concentración Mínima Inhibitoria ${ }^{(4,8)}$ y deben prolongarse por entre 4 a 6 semanas, hasta la normalización de la $\operatorname{VES}^{(8)}$.

\section{Antibioticoterapia (Edad/Germen)}

- En los recién nacidos (0 a 2 meses): $S$. aureus, estreptococo grupo $\mathrm{B}$, bacilos gram negativo (E. coli). Oxacilina más cefotaxima o gentamicina.

- Niños menores de 5 años: $S$. aureus, estreptococo del grupo A beta hemolítico, H. influenzae. Cefuroxima $150 \mathrm{mg} / \mathrm{kg} /$ día c/8 horas u oxacilina + cefotaxima o ceftriaxona.

- Niños mayores de 5 años: S. aureus. Oxacilina $100-150 \mathrm{mg} / \mathrm{kg} /$ día c/6 horas o cefazolina $100 \mathrm{mg} / \mathrm{kg} /$ día c/8 horas.

- Anemia drepanocitica: Salmonella. Oxacilina $150 \mathrm{mg} / \mathrm{kg} /$ día c/6 horas + cefotaxima $200 \mathrm{mg} / \mathrm{kg} /$ día c/6-8 horas.

- Postrauma: Pseudomonas aeuruginosa. Oxacilina $150 \mathrm{mg} / \mathrm{kg} /$ día c/6 horas + ceftazidime $150 \mathrm{mg} / \mathrm{kg} /$ día c/8 horas.

- En caso de pacientes alérgicos a betalactámicos y anaerobios se recomienda el uso de clindamicina $40 \mathrm{mg} / \mathrm{kg} /$ día c/6-8 horas.

\section{Tratamiento quirúrgico}

Está indicado llevar a sala de operaciones cuando se debe hacer drenaje de abscesos, si no hay respuesta al tratamiento antibiótico, hay artritis séptica concomitante, osteomielitis con signos graves de enfermedad y la necesidad de tomar una biopsia.

En cuanto a la técnica, se utiliza isquemia con manguito por elevación, sin usar venda de Esmach, incisión (no punción), debridamiento amplio y perforaciones corticales. Es muy 
controvertido el uso de sistemas de irrigaciónaspiración y si es necesario, el uso de fijador externo por pérdida en la estabilidad ósea.

\section{Resto de tratamiento}

Se basa en medidas generales para el cuadro febril: antipiréticos, hidratación y analgésicos. La inmovilización del miembro no es absolutamente necesaria (férula) las ventajas son: mejoría del dolor, retraso en la progresión del foco de osteomielitis. Usualmente es suficiente con 3 a 4 semanas de inmovilización.

\section{Pronóstico}

$\mathrm{Si}$ el diagnóstico es precoz y el tratamiento adecuado la morbilidad es escasa ( 1 a $2 \%$ ) y se refiere a cronificación, aumentando en los pacientes con tratamiento inadecuado (10 a 30\%).

Los factores que influyen en el pronóstico son:

a. Localización: recurrencia alta en metatarsos y rodilla.

b. Duración de los síntomas.

c. Virulencia de gérmenes.

d. Afectación articular.

e. Tratamiento quirúrgico y antibiótico adecuado.

\section{Formas clínicas especiales}

\section{Osteomielitis Subaguda hematógena}

El dolor es menos intenso, la temperatura normal o leve aumento y pocos síntomas sistémicos. Se suele diagnosticar a las 2 o 3 semanas del comienzo de los síntomas.

$\mathrm{Su}$ curso es subagudo, por la mayor resistencia a la infección, la menor virulencia bacteriana y la administración precoz de los antibióticos. Los gérmenes más frecuentes son $S$. aureus y $S$. epidermidis.

En los laboratorios la fórmula blanca es normal, la VES está aumentada en $50 \%$ de los casos, los hemocultivos casi siempre son negativos y el cultivo de punción local es negativo en $40 \%$ de los casos. La radiografía tiene alteraciones similares a la aguda.

\section{Clasificación de Roberts de la Osteomielitis subaguda hematógena:}

Tipo I. Metafisiaria:

IA: Zona de radiolucidez sin reacción inflamatoria (parecido a granuloma eosinófilo).

IB: Imagen ovoide de bordes netos $y$ esclerosos, de localización metafisiaria de predominio por huesos largos en especial en la tibia, cavidades óseas llenas de pus, tejido de granulación o fibroso $y$ característico por dolores nocturnos (absceso de Brodie).

Tipo II: Metafisiario con erosión cortical.

Tipo III: Diafisiario con reacción cortical y perióstica (parecido al osteoma osteoide).

Tipo IV: Diafisiario en capas de cebolla (parecido al sarcoma de Ewing).

Tipo V: Epifisiario, con áreas concéntricas de lucidez.

Tipo VI: En el cuerpo vertebral, con colapso del mismo.

El tratamiento consiste en apertura y curetaje del foco (suele encontrarse tejido de granulación, no pus), con forma de cultivo y antibiótico según el cultivo.

\section{Osteomielitis Crónica}

Se define por la presencia de focos residuales de infección (hueso avascular y suaves restos de tejido) que dan lugar a episodios recurrentes ${ }^{(9,10)}$. Es un cuadro clínico mayor a 6 semanas, el tiempo por lo general suele ser discutido.

\section{Etiopatogenia}

Las causas posibles ponderadas son: la evolución desfavorable a la cronicidad de la osteomielitis aguda hematógena, contaminación directa a través de herida o punción, a veces en el curso de las fracturas (lo más frecuente), también infección por contigüidad o por ejemplo cuerpo extraño y una prótesis metálica, que favorece la adhesividad bacteriana $^{(7,9)}$.

La cronificación de la infección es resultado del tratamiento inadecuado o tardío, debido a un retraso diagnóstico. El cuadro clínico tarda en instaurarse y las manifestaciones se atribuyen al traumatismo o al foco. 


\section{Clínica}

Curso prolongado con largos periodos de quiescencia salpicados de exacerbaciones. La primera de las exacerbaciones suele conllevar reapertura de herida y fistulas por las que drena material purulento de manera intermitente ${ }^{(7)}$. Las reagudizaciones presentan dolor local, secreción y aumento de la VES. A veces, sólo se manifiesta como retardo o ausencia de la consolidación de la fractura.

\section{Anatomía Patológica}

Similar a la osteomielitis aguda, salvo en el fenómeno de destrucción y reparación entremezcladas. Los secuestros están presentes casi siempre y las fístulas con más frecuencia. Hay intensa reacción ósea de vencidad, esclerosis periférica importante, infiltrado inflamatorio linfomonocitario y la presencia de tejido de granulación, fibrosis y neoformación ósea $^{(7)}$.

Determinados microorganismos, en especial los estafilococos coagulasa negativos sintetizan una serie de sustancias (exopolímeros) que envuelven la bacteria, formando glucocálix (también denominado slime, moco o limo); éste favorece la adhesión al hueso e impide la acción de los fagocitos, los anticuerpos y el complemento, así como de los antibióticos, dificultando la curación de la infección ${ }^{(7)}$.

\section{Radiología}

Inicialmente puede observarse desmineralización generalizada, engrosamiento perióstico, osteocondensación y engrosamiento cortical, sobre todo a nivel metafisiario. Posteriormente, geodas con secuestros (se ven mejor en el TAC).

\section{Clasificación (Cierny y Mader)}

Busca racionalización del tratamiento.

Para la gradación fisiológica se debe tener en cuenta enfermedades previas y actuales, aspectos sociolaborales y psicológicos. Tres clases fisiológicas:

a. Buen estado general y buena vascularización. Viabilidad de tejidos con respuesta normal a infección y cirugía. b. Patología local y/o sistémica que compromete el resultado y el pronóstico.

c. Resultados de tratamiento potencialmente más dañinos que el cuadro infeccioso.

Para la gradación anatómica o local se usa exploración física y diagnóstico por imágenes.

Hay cuatro tipos anatómicos:

1. Medular.

2. Superficial: con afectación de la superficie cortical externa.

3. Localizada: con secuestros y/o cavitaciones de todo el espesor cortical sin compromiso de la estabilidad del segmento afectado.

4. Difusa: Se añade inestabilidad mecánica.

Combinado ambas gradaciones, se obtiene los 12 estadios clínicos. El tratamiento se aplica en consonancia con el estadio en que se encuentra el paciente.

\section{Tratamiento}

Tratamiento previo

a. Tratamiento de los defectos inmunológicos.

b. Tratamiento de las deficiencias nutricionales.

c. Suplementos nutricionales.

Los principios generales en el tratamiento de la osteomielitis crónica es meramente quirúrgico ${ }^{(9)}$. El momento de la intervención quirúrgica es controversial. Algunos autores recomiendan secuestrectomía temprana para erradicar la infección y proporcionar un mejor ambiente para el periostio. Otros recomiendan esperar hasta que haya un involucro, antes de realizar una secuestrectomía, para minimizar los riesgos de complicaciones como fracturas, pseudoartrosis y deformidad. En cualquiera de los casos es fundamental conservar el involucro ${ }^{(9)}$.

\section{Antibioticoterapia}

La selección se basa en específico según el cultivo óseo, penetración del tejido óseo y la del glucocálix (vancomicina y teicoplanina se adhieren a los exopolisacáridos). Actividad 
intracelular: rifampicina, fluoroquinolonas, quatrimoxazol, clindamicina, fosfomicina, linezolid.

También en la combinación de poliantibioticoterapia, duración y vía de administración: corta (4 a 6 semanas), prolongada (bacterias intracelulares) e intravenosa: 1 a 2 semanas y después oral.

La vía oral y la parenteral tienen una tasa de éxito consistentemente similar. Considerando que la vía oral es más sencilla para el paciente, evita riesgos asociados con catéteres intravenosos y es menos costosa ${ }^{(6)}$.

\section{Complicaciones}

Casos de reagudizaciones asociados a artritis séptica o fracturas patológicas.

\section{Formas clínicas especiales de Osteomielitis crónica}

\section{Osteomielitis multifocal crónica}

El inicio es insidioso, los síntomas fluctuantes durante años. Las lesiones óseas simétricas y bilaterales en la metáfisis de huesos largos (tibia, fémur y clavícula). También puede darse la presencia de lesiones líticas predominantes en radiografía.

Las pruebas de laboratorios por lo general son normales salvo VES y los cultivos negativos.

El pronóstico a largo plazo es favorable, por lo que a veces no tienen indicación de tratamiento antibiótico.

\section{Osteomielitis crónica esclerosante de Garré}

La causa es desconocida. Podrían ser gérmenes poco virulentos (probablemente anaerobios). Con mayor frecuencia afecta niños y adultos jóvenes. En la clínica el dolor es crónico intermitente, a veces con tumefacción. La radiografía muestra hipertrofia y densificación cortical diafisiaria. $\mathrm{La}$ VES está discretamente elevada.

Los pacientes presentan antecedentes personales de osteomielitis crónica de bajo grado. A veces hay lesión secundaria a distancia.
El diagnóstico diagnóstico diferencial debe hacerse con osteoma osteoide y Paget.

\section{Forma neurálgica de Gosselin}

Es una afectación más específica de la inervación del hueso. Es la osteomielitis esclerosante que cursa con dolores intensos de predominio nocturno.

\section{Forma fibrosa de Phemister}

Causa reacción fibrosa con cavidad quística con contenido fibroso, el hueso es frágil con la presencia de fracturas patológicas frecuentes.

El diagnóstico diferencial debe hacerse con la displasia fibrosa.

\section{Osteomielitis por gérmenes específicos}

\section{Micobacterias (tuberculosis)}

Se ha visto un aumento en el número de casos relacionados por inmunodeficiencia. La vía hematógena (foco: epífisis en el adulto y metáfisis en el niño) es la forma más frecuente de propagación. Si es de comienzo articular evoluciona más lento que si es de comienzo óseo. Más frecuente en vértebras, seguido de rodilla en adultos, sacroilíacas y cadera en niños ${ }^{(7)}$. El dolor es localizado con curso insidioso ${ }^{(7)}$.

La radiografía muestra osteoporosis subcondral y osteolisis periarticular.

El líquido sinovial muestra el cultivo positivo en 80 a $90 \%$ de los casos, tinción Ziehl-Neelsen positiva en $20 \%$ de los casos.

El tratamiento se basa en antibióticoterapia antituberculosa, reposo articular y a veces cirugía.

\section{Espiroquetas}

\section{a. Treponema pallidum:}

En sífilis congénita se da osteocondritis metafisiaria de huesos largos (desaparece espontáneamente a los seis meses) y periostitis más prolongada. En la pubertad, puede haber sinovitis bilateral indolora en rodillas y codos. Tibia en sable en el 4\% de los casos. En el caso de que sea sífilis secundaria, las artralgias, la artritis y la tenosinovitis son predominantes. La 
sífilis terciaria se caracteriza por sinovitis de grandes articulaciones. La neurosífilis puede asociarse a degeneración articular neurógena (articulaciones de Charcot).

\section{b. Borrelia burgdorferi:}

Asociada a la enfermedad de Lyme por picadura de garrapata (sobre todo Ixodes danmini). Inicialmente eritema crónico migratorio. Semanas o meses después de alteraciones neurológicas, cardíacas, poliartralgias (artritis en grandes articulaciones), tenosinovitis, entre otras. El tratamiento debe ser precoz (tetraciclina o amoxicilina).

\section{Virus}

Poliartritis autolimitadas en rubéola, hepatitis B y VIH.

Enfermedad de Caffey (Hiperostosis cortical infantil). La causa es desconocida, se postula que puede ser por un germen desconocido. En la clínica se evidencia inflamación de tejidos blandos con fiebre alta y reacción perióstica en la radiografía. Predominio en cráneo, mandíbula, clavícula, escápula y costillas. No precisa de tratamiento, sólo medidas profilácticas.

\section{Fiebre Tifoidea}

Osteomielitis costal, condrocostal, vertebral y en miembros inferiores.

\section{CONCLUSIONES}

Gracias al diagnóstico preciso y acertado de cuadros de osteomielitis aguda hematógena, en la actualidad los casos han disminuido sustancialmente. No obstante persisten y es importante que desde el inicio se identifique con una buena valoración de la historia clínica, evolución y exámenes.

Se debe tener en cuenta que cualquier complicación tardía de la enfermedad, puede llevar a secuelas que afecten el resto de la vida cotidiana del paciente, en especial si se tratan de casos pediátricos.

La osteomielitis ha tomado importacia en pacientes con factores de riesgo como inmunosupresión, ya que muestran una evolución tórpida, pacientes a quienes se les ha colocado materiales de osteosintesis, protésis e instrumentaciones que llegan a complicarse, de igual manera cuadros con clínica insidiosa y que evolucionan a la cronicidad. Todos requieren un diagnóstico rápido y tratamiento precoz con altas dosis.

Se debe tomar en cuenta los casos menos frecuentes; los gérmenes que no son comunes pero que pueden enlentecer un diagnóstico sino se conoce su clínica.

\section{REFERENCIAS BIBLIOGRÁFICAS}

1. Lew D Waldvogel F. Osteomyelitis. N Engl J Med 1997;226(14):999-1007.

2. Wilson S Skinner H. Diagnóstico y tratamiento en ortopedia. Infecciones ortopédicas. Capítulo 8. Edición $4^{\mathrm{a}}$. Editorial Mc Graw Hill, 2006;421-450.

3. Lipsky B Berendt A Cornia P et al. 2012 Infectious Diseases Society of America Clinical Practice Guideline for the Diagnosis and Treatment of Diabetic Foot Infections. IDSA Guidelines, 2012;54:3-73.

4. Minguella J. Protocolo: Infección Osteoarticular. Unidad de Enfermedades Infecciosas de Pediatría. Unidad de Ortopedia Pediátrica. Hospital Vall dHebron. Barcelona 2001. Edición 2a ;1-11.

5. Mayank R Somerson J Kerr K Conroy J. Pathophysiology and Pathogenesis of Osteomyelitis. University of Texas Health Science Centre, San Antonio, Texas. Harrogate District Hospital, North Yorkshire, 2012;318.

6. Spelberg B Lipsky B. Systemic Antibiotic Therapy for Chronic Osteomyelitis in Adults. Invited article in Clinical Practice, 2012;54:393-403.

7. Aguado García J.M. Osteomielitis. Unidad de enfermedades infecciosas. Hospital Universitario, Madrid, 2002;4525-4528.

8. Kaplan S. Osteomyelitis in Children. Infectious Disease Clinics of North America, 2005;19:787-797.

9. Spiegel D Norgrove J. Chronic Osteomyelitis in Children. Techniques in Orthopedics 2005;20 (2):142-151.

10. Gutiérrez D Ruiz E Carmona F García O. Protocolo diagnóstico de la osteomielitis. Servicio de Medicina Interna. Hospital 
Universitario Puerta del Mar 2010;35913593.

11. Zimmerli W. Vertebral Osteomyelitis. New Engl J Med 2010;362(11):1022-1028.

12. Frainmow H. Systemic Antimicrobial Therapy in Osteomyelitis. University of Medicine and Denistry of New Jersey, Robert Wood Johnson Medical School, Division of Infectious Diseases, Cooper University Hospital, Camden, New Jersey. Seminars in Plastic Surgery 2009;23(2):90-98.

13. Porucznik M. Telling the difference: $M R S A$ or MSSA Osteomyelitis. AAOS 2011;1-3.

14. Cierny G Mader J Penninck J. A Clinical Staging System for Adult Osteomyelitis. Clinical Orthopedics and Related Research, 2003;414:7-23.

15. Agúndez B Molina C Sentchordi L. Osteomielitis. Infecciones en Pediatría. Guía rápida para la selección de antimicrobiano empírico, 2011;1:4-7.

16. Wolfe R. Case Report: Treatment of Chronic Osteomyelitis. Division of Infectious Disease, Duke University Medical Center, Durham, North Carolina, 2011; 538-540.

17. Offiah A. Acute osteomyelitis, septic arthritis and discitis: Difference between neonates and older children. European Journal of Radiology 2006;60:221-232.

18. Juutilainen V. Posttraumatic osteomyelitis. Department of plastic surgery, Helsinki University Hospital Finland. Suomen Ortopedia Traumatologia 2011;34:38-41.

19. Grau L Galleano H Rodríguez M Castro H. Osteomielitis de Rótula. Reporte de caso en un paciente pediátrico. Servicio de pediatría. Hospital Central Dr. Emilio Cubas Instituto de Previsión social. Postgrado de infectología pediátrica. Universidad Católica Nuestra Señora de la Asunción, Paraguay, 2012;39(2):117-120.

20. García de la Rubia S Pérez T. Infecciones osteoarticulares: Osteomielitis hematógena aguda. Osteomielitis crónica. Artritis Aguda. Pediatría integral 2002;6(6):519-532.

21. Nadeem S Nadeem M Tahir M Khawaja T. Drug Therapy in Osteomyelitis. Department of pharmacy, Lahore College For Women University 2010;2(2):67-75.

22. Rodner C Browner B Pesanti E. Chronic Osteomyelitis. Section I: General Principles Chapter 19. 2003; 483-503.

23. Hashmi M Norman P Saleh M. The management of chronic osteomyelitis using the lautenbach method. The journal of bones and joint surgery, 2004;8(2):269-274.

24. Boeck H. Osteomyelitis and septic arthritis in children. Acta orthopedic Belgic 2005;71:505-514. 